\title{
Clinical and histologic characteristics of breast cancers in women with previous pathologic diagnosis of benign breast disease in Spain
}

Authors: M. Román ${ }^{1,2}$, M. Caicoya ${ }^{1,2}$, J.A. Espinàs ${ }^{3}$, M. Sala ${ }^{1,2}$, I. Torá-Rocamora ${ }^{4}$, M.J. Quinta ${ }^{5}$, M.

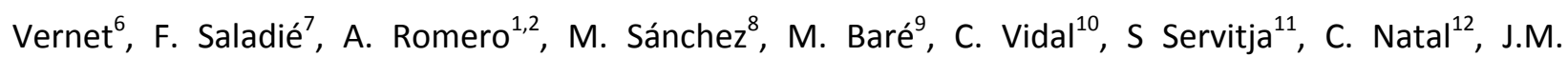
Corominas $^{13}$, J. Ferrer ${ }^{14}$, A. Rodríguez-Arana ${ }^{15}$, X. Castells $^{1,2}$, on behalf of the BELE Project study group.

1. Department of Epidemiology and Evaluation, IMIM (Hospital del Mar Medical Research Institute), Barcelona, Spain;

2. Research Network on Health Services in Chronic Diseases (REDISSEC), Barcelona, Spain

3. Department of Health, Catalan Cancer Plan, Barcelona, Spain

4. Preventive Medicine and Epidemiology Department, Hospital Clinic, Barcelona, Spain

5. Epidemiology Department, Hospital de la Santa Creu i Sant Pau, Barcelona, Spain

6. Department of Obstetrics and Gynecology, IMIM (Hospital del Mar Medical Research Institute), Barcelona, Spain

7. Breast Cancer Screening Program of Tarragona, The Foundation League for the Research and Prevention of Cancer, Tarragona, Spain.

8. General Directorate of Public Health, Government of Cantabria, Santander, Spain;

9. Clinical Epidemiology and Cancer Screening, Parc Taulí University Hospital, Sabadell, Spain

10. Cancer Prevention and Monitoring Program, Catalan Institute of Oncology, Barcelona, Spain

11. Department of Oncology, IMIM (Hospital del Mar Medical Research Institute), Barcelona, Spain

12. Breast Cancer Screening Program, Principality of Asturias, Oviedo, Spain

13. Department of Pathological Anatomy, IMIM (Hospital del Mar Medical Research Institute), Barcelona, Spain

14. Radiology Department, Hospital de Santa Caterina, Girona, Spain

15. Department of Image Diagnostics, IMIM (Hospital del Mar Medical Research Institute), Barcelona, Spain

Corresponding author: Xavier Castells, Ph.D

Department of Epidemiology and Evaluation, IMIM (Hospital del Mar Medical Research Institute), Passeig Marítim 25-29, 08003 Barcelona, Spain

e-mail: xcastells@parcdesalutmar.cat

Running tittle: Characteristics of breast cancers in women with a benign breast disease

Key words: Breast neoplasm, benign breast disease, prognostic factors. 


\section{ABSTRACT:}

Background: Women with a benign breast disease (BBD) have an increased risk of subsequent breast carcinoma. Information is scarce regarding the characteristics of breast carcinomas diagnosed after a BBD. Our aim was to point out the differences in clinical and histological characteristics of breast carcinomas diagnosed in women with and without a previous pathological diagnosis of BBD in the context of population-based mammography screening.

Methods: Retrospective cohort study of all women aged 50-69 years who were screened at least once in a population-based screening program in Spain, between 1994 and 2011 and followed-up until December 2012. The mean follow-up was 6.1 years. We analyzed 6,645 breast carcinomas, of whom 238 had a previous pathological diagnosis of BBD. Information on clinical and histologic characteristics was collected from pathology reports. Logistic regression was used to estimate the odds ratio (OR) and 95\% confidence intervals $(95 \% \mathrm{Cl})$ of occurrence of selected histological characteristics of breast carcinomas in women with and without a previous BBD.

Results: Women with a previous BBD had a higher proportion of Ductal Carcinoma In Situ (DCIS) compared with women without a BBD (22.1\% and $13.6 \%$, respectively). Among those diagnosed with an invasive breast carcinoma, women with previous BBD were more likely to be diagnosed with carcinomas sized $>2 \mathrm{~cm}(\mathrm{OR}=1.46 ; 95 \% \mathrm{Cl}=1.03-2.08)$, metastatic positive $(\mathrm{OR}=2.66 ; 95 \% \mathrm{Cl}=1.21-5.86)$, and with a high Ki-67 proliferation rate $(\mathrm{OR}=1.93 ; 95 \% \mathrm{Cl}=1.24-2.99)$. No differences were found across histologic subtypes of BBD.

Conclusions: Screening participants with a previous pathological diagnosis of BBD had a higher proportion of DCIS. However, invasive carcinomas detected in women with a BBD were associated with clinical and histological characteristics conferring a worst prognosis. 


\section{INTRODUCTION}

Population-based mammography screening for breast cancer entails a number of benign breast findings at biopsy recommendation to rule out malignancy, referred to as benign breast disease (BBD). It is estimated that $1.8 \%$ of women aged 50 to 69 years participating regularly in the mammographic screening program in Spain will have a biopsy recommendation with a benign outcome (1). Women with BBD are at a substantially increased risk of subsequent breast cancer (2-5). Among women with a BBD, non-proliferative breast diseases have been shown to have a moderate elevated risk of subsequent breast cancer (2), but the risk has been found to be higher for proliferative disease without atypia, and highest for proliferative disease with atypia (2-4). However, the European Guidelines for Quality Assurance in Breast Cancer Screening and Diagnosis do not provide specific recommendations for the clinical management of women with a pathological diagnosis of BBD at mammography screening (6).

Due to their increased risk of breast cancer women with BBD may benefit from a personalized breast cancer screening strategy. These strategies aim at improving the balance of benefits and harms of breast cancer screening by offering different frequency and modality of screening to women invited based on their breast cancer risk $(7,8)$.

There is lack of evidence on whether the clinical and histological characteristics of breast carcinomas may differ in women with and without a previous BBD (9-11). The studies yielded contradictory results, and none of them is performed in the context of population-based mammography screening. We aimed to point out the differences in clinical and histological characteristics of breast cancers diagnosed in women with and without a previous pathological diagnosis of BBD in the context of population-based mammography screening in Spain. 


\section{METHODS}

\section{Setting and study population}

Population-based screening in Spain started in 1990 in one region and became nationwide in 2006. Breast cancer screening in Spain is government-founded and follows the recommendations of the European Guidelines $(12,13)$. The setting of the study has been described in detail elsewhere $(2)$. In brief, women aged 50 to 69 years are biennially invited for a two-view mammography. Screening mammograms are interpreted by trained breast radiologists. Prior mammograms are retrieved for comparison at subsequent screens. The Breast Imaging Reporting and Data System (BI-RADS) scale was used to classify mammograms. Women with screening mammograms scored with BIRADS 3,4 , 5 , or 0 are recalled for further assessments within a maximum of 2 months after the screening test to confirm or rule out malignancy.. Further assessments may include additional imaging, ultrasound and invasive procedures. If malignancy is ruled out women are referred back to routine screening at two years. Women diagnosed with a breast carcinoma are referred for treatment. All breast biopsies were histopathologically classified by trained pathologist.

The initial population consisted of individual level data from all 549,422 women screened at least once in the breast cancer screening program in Spain in the period 1994-2011, with follow-up until December 2012. The recall rate for the population was $5.4 \%$, with a false-positive result rate of $4.7 \%$. The detection rate and rate of interval cancer were 4.0 and 1.3 per 1,000 screens, respectively. Full-field digital mammography was introduced in the program in 2004 and was gradually widespread in the following years, with an overall rate of $26 \%$ full-field digital mammograms in the study period. We restricted the study population to all 9,375 women with a diagnosis of breast carcinoma during the study period (invasive carcinoma or ductal carcinoma in situ (DCIS)). We excluded breast cancer cases detected at first screen, as they could not have had a BBD detected at screening previous to the diagnosis of the breast carcinoma $(n=2,730)$. This left 6,645 breast carcinomas for analyses (Figure 1). Data was obtained from the databases of the screening regions and the study was approved by the 
ethics committees of the institutions that provided data. Informed consent was not required because we used anonymized retrospective data.

\section{Characteristics of breast carcinomas and classification of benign breast diseases}

We included all breast carcinomas diagnosed as a screen detected or interval carcinoma. An interval breast cancer was defined as a breast carcinoma diagnosed after a negative screening test, or after a positive screening test were malignancy is finally ruled out, either before the next biennial invitation to screening, or within two years for women who had reached the upper age limit for screening. Because there is no nationwide cancer registry in Spain, interval carcinomas were identified by linking population based registries (regional Minimum Basic Data Set, regional cancer registries), and hospital-based cancer registries with screening population data, which ensured a high compliance of interval breast cancer cases.

Information on clinical and histological characteristics of breast carcinomas and the histology of pathologically diagnosed BBD was collected from pathology reports. For breast carcinomas we collected information on breast cancer type (DCIS or invasive carcinoma), grade of differentiation, tumor size, lymph node involvement, distant metastasis, estrogen receptors (ER), progesterone receptors (PR), human epidermal growth factor receptor 2 (HER2), and cellular marker for proliferation Ki-67. Biomarker assessment was performed as part of the diagnostic process. The positivity criteria used by each hospital followed international recommendations and their updates throughout the study period $(14,15)$. Breast carcinomas were considered positive when more than $10 \%$ of cells stained positive for Ki67. Grade of differentiation was defined according to the Scarff-Bloom-Richardson criteria, modified by Elson (16). BBD were categorized according to their histology based on the classification suggested by Page and Dupont and the College of American Pathologist as non-proliferative, proliferative without atypia, and proliferative with atypia (17). Because the number of women with a breast cancer diagnosis after a proliferative BBD is small in the context of breast cancer screening, we merged the categories proliferative without atypia, and proliferative with atypia into a unique category called proliferative. 
Because the use of fine needle aspiration biopsies to rule out malignancy is common in breast cancer screening and they usually yield a nonspecific histological classification if breast carcinoma is discarded, we included the category negative for malignant cells.

\section{Statistical analyses}

For simplicity of presentation of results the study variables were categorized as: age at last screening exam (50-54, 55-59, 60-64, and 65-69 years), detection mode (screen detected or interval carcinoma), breast cancer type (DCIS or invasive carcinoma), grade of differentiation $(1,2$, or 3$)$, tumor size $(\leq 2 \mathrm{~cm}$, or $>2 \mathrm{~cm}$ ), lymph node involvement (negative or positive), distant metastasis (negative or positive), ER status (negative or positive), PR status (negative or positive), HER2 status (negative or positive), and Ki-67 proliferation status (high or low).

Breast cancer characteristics were compared among women with and without a previous pathological diagnosis of BBD using Chi-squared tests and z-tests for column proportions. Among invasive breast carcinomas, we used logistic regression to estimate the odds ratio (OR) and $95 \%$ confidence intervals $(95 \% \mathrm{Cl})$ of occurrence of the clinical and histological characteristics of interest in women with a previous BBD compared with women without a BBD. We performed separated analyses for each of the breast cancer characteristic of interest (grade of differentiation, tumor size, lymph node involvement, distant metastasis, ER status, PR status, HER2 status, and Ki-67 status). All models were adjusted for age at last screening exam (continuous), calendar year at last screening exam (continuous), and detection mode. All tests were two-sided with a 5\% significance level. Statistical analyses were conducted in SPSS v.21 (IBM) and R statistical software version 3.2.3 (www.r-project.org).

Because information on breast cancer characteristics was missing for some women in the study population we performed a sensitivity analysis to compare the distribution of age at last screening exam, detection mode and year at last screening exam in women with and without missing information on these variables. 


\section{RESULTS}

We analyzed 6,645 women with a diagnosis of breast cancer, of whom 238 (3.6\%) had a previous pathological diagnosis of BBD. Amongst the breast carcinomas , 4,450 (67.0\%) were screen detected and 2,195 (33.0\%) were interval carcinomas. A higher proportion of DCIS was found in women with than in women without a previous BBD $(22.1 \%$ and $13.6 \%$, respectively; $p<0.05)$ (Table 1$)$. No significant differences were found in age distribution, or mode of detection between women with and without a BBD (Table 1).

Among invasive breast carcinomas, women with previous BBD had a higher proportion of invasive carcinomas that were sized $>2 \mathrm{~cm}(36.7 \%$ vs $26.4 \%)$, metastatic positive ( $5.2 \%$ vs $1.7 \%$, respectively), and with a high Ki-67 proliferation rate ( $50.5 \%$ vs $33.7 \%$, respectively), compared with women without a BBD (Table 2). No differences were found in the grade of differentiation, lymph node involvement, ER status, PR status and HER2 status.

The analyses stratified by detection mode, showed a consistent higher proportion of DCIS and high Ki-67 invasive carcinomas among women with a pathological diagnosis of BBD for both, screen detected and interval carcinomas (Table 3). Among women with an interval carcinoma, the proportion of DCIS was four times larger in women with than in women without a previous benign breast disease (19.7\% vs $5 \%)$. Half of the invasive breast carcinomas diagnosed in women with a previous benign breast disease had a high Ki-67 proliferation status for both, screen detected and interval carcinomas. A higher proportion of grade 1 breast carcinomas was observed in women with than in women without a BBD among screen detected cancers (35.4 vs $27.6, p<0.05$ ), but not for interval carcinomas (18.6 vs 16.7 , respectively). No significant differences in tumor size, lymph node involvement, distant metastasis, ER status, PR status and HER2 status were found between women with and without previous BBD for neither screen detected nor interval carcinomas.

Shown in Table 4 are the clinical and histological characteristics of breast carcinomas by subcategory of pathologically diagnosed BBD. Compared with women without a BBD, women with nonproliferative lesions had a higher proportion of DCIS (Table 4). Among invasive carcinomas, women with 
non-proliferative lesions had a higher proportion of tumors sized $>2 \mathrm{~cm}$ and high Ki-67 proliferation rate, whereas women with a proliferative BBD had a higher proportion of metastatic invasive carcinomas at diagnosis. Women with a BBD negative for malignant cells showed no significant differences compared with women without a BBD. No differences were found across the sub-categories of BBD compared to each other.

The adjusted regression model for invasive carcinomas showed that women with a previous pathological diagnosis of BBD were more likely to have a tumor sized $>2 \mathrm{~cm}(\mathrm{OR}=1.46 ; 95 \% \mathrm{Cl}$ : $1.03-$ 2.08), distant metastatic positive $(\mathrm{OR}=2.66 ; 95 \% \mathrm{Cl}: 1.21-5.86)$ and with a high Ki-67 proliferation rate $(\mathrm{OR}=1.93 ; 95 \% \mathrm{Cl}: 1.24-2.99)$ (Table 5), compared with women without a BBD. 


\section{DISCUSSION}

Women with a previous pathological diagnosis of BBD were more likely to be diagnosed with a DCIS rather than an invasive carcinoma compared with women without a BBD. However, invasive carcinomas diagnosed in women with a BBD were associated with worst prognosis characteristics such as size $>2 \mathrm{~cm}$, positive distant metastasis and high $\mathrm{Ki}-67$ proliferation rate. To our knowledge, this is the first study to compare the clinical and histological characteristics of breast carcinomas in populationbased mammography screening in women with and without a previous BBD.

Previous research indicates that women with a BBD are at a higher risk of developing subsequent breast carcinoma $(2,4,5)$. It is important to highlight not only the increased risk found in women with $\mathrm{BBD}$, but also the worst prognosis characteristics associated with their invasive breast carcinomas. Some of the most relevant prognostic factors in breast cancer are tumor stage (tumor size, lymph node status, and presence of distant metastasis), hormone receptor status, HER2 overexpression, and Ki-67 status. We found a higher proportion of invasive carcinomas sized $>2 \mathrm{~cm}$, metastatic positive, and with a high Ki-67 proliferation rate among women with previous pathological diagnosis of BBD. The worst prognosis characteristics may indicate detrimental biology features of these carcinomas (11), and in particular a higher Ki-67 proliferation rate is indicator of a faster growing pattern (18).

Few studies have analyzed clinical and histological characteristics of breast carcinomas in women with previous BBD, and they yielded inconclusive results (9-11). Two studies, performed in a clinical setting, compared clinico-pathologic characteristics of breast carcinomas across histologic categories of previous BBD. The studies lacked a reference group of women without a BDD, which makes comparisons with our study misleading $(9,11)$. One of the studies found no differences across categories of BBD, while the other found that women with atypical hyperplasia had a higher frequency of grade 1 and ER+ breast carcinomas compared with women with proliferative disease without atypia or non-proliferative disease. On the other hand, Mitro et al. performed a study in a population of African-American women in the US using a reference population of women with a breast cancer without a previous BBD, which makes results more comparable with our study (10). The study suggested that women with BBD may 
have better prognosis characteristics than women in the general population. They reported a higher proportion of in situ, grade 1 and hormone receptor positive carcinomas in women with a BBD. However, the differences in grade of differentiation and hormone receptors disappeared almost entirely after adjusting for in situ vs. invasive carcinoma, which gives consistency to the idea that breast cancer type plays an important role in the characterization of breast carcinomas diagnosed after a BBD. The findings of the study could improve clinical knowledge and guide individualized screening recommendations. Studies on long term mortality and survival are needed to support the idea of a better or worst prognosis of breast carcinomas diagnosed in women with a pathological diagnosis of BBD at breast cancer screening.

We found a higher proportion of DCIS in breast carcinomas diagnosed in women with a BBD, which has previously been reported (10). The difference may indicate that women with a pathologically diagnosed BBD are more likely to be aware of their health status and attend biennial screening regularly. However, the analyses stratified by detection mode showed a similarly increased proportion of DCIS in women with a BBD for screen detected and interval carcinomas. It is important to remark that following the European Guidelines, women with a BBD detected at screening do not follow different screening recommendations than women with negative screening tests. On a previously published work we found a higher proportion of DCIS in women with a previous biopsy with a benign result compared with women with negative screening tests only (19). Also, we found no differences in the proportion of DCIS across the BBD subtypes, which is consistent with previous results (11).

The role of tumor size in the differences found between women with and without a BBD has yielded contradictory results. The above mentioned study by Mitro et al showed no differences in tumor size between women with and without a BBD, whereas the study carried out in Spain by Domingo et al. showed a higher proportion of tumors sized $>2 \mathrm{~cm}$ in women with a biopsy with benign result compared with women with negative screening tests $(10,19)$. In agreement with previously reported data we found no differences in tumor size across subtypes of BBD (11). 
We found that ER, PR and HER2 receptor status were not histological characteristics distinctive between women with and without a BBD. Our findings of an absence of differences in the hormone receptor status are in agreement with a previous study (10). Neither did we find differences in the proportion of $\mathrm{ER}+$, or $\mathrm{PR}+$ invasive breast carcinomas across BBD subtypes, which is in agreement with a previous study (9), but not with other (11) that found a higher proportion of ER+ invasive carcinomas in women with proliferative lesions with atypia compared with women with non-proliferative lesions and women with proliferative lesions without atypia. It has been suggested that tissue concentration of estradiol in BBD is higher than in normal breast tissue (20), which could favor a later development of ER+ invasive carcinomas in women with BBD. Women diagnosed with lobular carcinoma in situ are routinely derived outside the screening program setting for clinical follow-up. Thus, we could not perform separate analysis for this entity, which could have been desirable given its possible link with certain types of invasive breast cancer (9).

In our study population $3.6 \%$ of breast carcinomas were diagnosed in women with a previous pathological diagnosis of BBD. A study assessing breast cancer risk in women targeted for mammography screening reported that the proportion of breast carcinomas diagnosed in women with a previous BBD, that was not self-reported, was 3.7\% (21). Studies carried out in a clinical setting have reported larger numbers of breast carcinomas in women with a previous pathological diagnosis of BBD (11). However, comparisons with clinical studies in absolute numbers are difficult because they lack a balanced reference population of women without a BBD. Most differences found between our study and previously published clinical studies could be explained by the study setting. First, the basis of our study population is a cohort of asymptomatic women biennially screened for breast cancer, which substantially differs from clinical studies where most women had a biopsy recommendation because of self-declared symptoms. Second, we did not include in our analyses BBD that were self-reported at the time of screening mammography. This inclusion criteria ensures that all BBD included for analyses were radiologically and pathologically confirmed, and diagnosed in asymptomatic women, which is the basis of a population-based screening program. 
A major strength of this study is that data were obtained from a well-established populationbased screening program with an average participation of $67 \%$ of invited women, and a re-attendance rate of $91.2 \%$ (12). We analyzed data from over 16-years of follow-up and 550.000 women aged 50-69 years screened at least once in the program, which minimizes selection bias. However, the study has several limitations. Firstly, the study was limited by the number of women with missing information for some histological characteristics, particularly hormonal receptors and Ki-67 status, which limits some interpretations. The sensitivity analyses showed a higher proportion of missing data on the earliest years after start of the screening program, because information on ER, PR, HER2 or Ki-67 was not routinely collected at that time (supplementary material). We also found that the proportion of missing data was larger among interval carcinomas, which was expected given that information on interval carcinomas was identified by linkage with external sources of information that do not systematically collect information on breast cancers characteristics. Also, we found small variations in the age distribution between women with and without missing information, although the distribution was consistently similar between women with available data and women with missing information on clinical and histological characteristics. Secondly, we had a reduced number of women with breast carcinoma after a BBD, which entails a small sample size for some subgroup analyses. Consequently, some results should be interpreted with care. Another limitation of the study is that women screened in 2011 were followed-up until December 2012 for interval carcinomas, which shortens the usual 24 months followup period. However, because the aim of the study was not to estimate breast cancer incidence but to compare the clinical and histological characteristics of breast carcinomas among women with and without previous BBD it is unlikely that a shorter follow-up for interval carcinomas has any effect on the characteristics studied.

\section{CONCLUSIONS}

Our study suggests that although women with a pathological diagnosis of BBD are more likely to develop a DCIS compared with women without a BBD, their invasive carcinomas are associated with clinical and 
histological characteristics conferring a worst prognosis, such as tumor size $>2 \mathrm{~cm}$, distant metastasis and a high Ki-67 proliferation rate. In addition to increasing the breast cancer risk, BBD pathologically diagnosed at screening could predict two types of breast carcinomas; the slow growing type identified by a higher proportion of DCIS, but also breast cancers with worse prognosis characteristics among those with an invasive carcinoma. This information widens the knowledge about the natural history of breast carcinomas in women with a previous BBD diagnosed at screening. Women with a BBD could benefit from a closer surveillance that should be considered when more personalized screening strategies are discussed. 
Acknowledgments: This work was supported by Grants from Instituto de Salud Carlos III FEDER, (PI11/01296), and (PI15/00098), and from the Network for Research into Healthcare in Chronic Diseases, REDISECC (RD12/0001/0015). The authors acknowledge the Benign Lesion (BELE) Study Group, listed here in alphabetical order and grouped by institution: (a) IMIM (Hospital Del Mar Medical Research Institute), Barcelona, Spain: Andrea Burón, Xavier Castells, Josep Maria Corominas, Ana Rodríguez-Arana, Marta Román, Maria Sala, Sònia Servitja, Isabel Torá-Rocamora, and Mar Vernet; (b) Corporació Sanitària Parc Taulí, Sabadell, Spain: Xavier Andreu and Marisa Baré; (c) Catalan Institute of Oncology, Barcelona, Spain: Llucia Benito Aracil and Carmen Vidal; (d) Hospital de la Santa Creu i Sant Pau, Barcelona, Spain: María Jesús Quintana, Margarita Posso, and Judit Solà-Roca; (e) General Directorate of Public Health, Department of Health, Government of Cantabria, Spain: Mar Sánchez; (f) Principality of Astúrias Health Service, Spain: Carmen Natal; (g) Fundació Lliga per a La Investigació i Prevenció Del Câncer, Universitat Rovira i Virgili, Tarragona, Spain: Jaume Galceran and Francina Saladié; (h) Hospital Santa Caterina, Girona, Spain: Joana Ferrer; and (i) Catalonian Cancer Strategy, Department of Health, Barcelona, Spain: Josep Alfons Espinàs

Conflict of interest statement: The authors declare that they have no conflict of interest. The funding sources had no role in the performance of the study or in the preparation of the manuscript.

Ethical Approval: Data used in the study was approved by the ethics committees of the institutions that provided data. Informed consent was not required because we used anonymized retrospective data 


\section{REFERENCES}

1. Roman R, Sala M, Salas D, Ascunce N, Zubizarreta R, Castells X. Effect of protocol-related variables and women's characteristics on the cumulative false-positive risk in breast cancer screening. Ann Oncol. 2012;23:104-11.

2. Castells $X$, Domingo L, Corominas $J M$, et al. Breast cancer risk after diagnosis by screening mammography of nonproliferative or proliferative benign breast disease: a study from a population-based screening program. Breast Cancer Res Treat. 2015;149:237-44.

3. Dyrstad SW, Yan Y, Fowler AM, Colditz GA. Breast cancer risk associated with benign breast disease: systematic review and meta-analysis. Breast Cancer Res Treat. 2015;149:569-75.

4. Hartmann LC, Sellers TA, Frost MH, et al. Benign breast disease and the risk of breast cancer. $N$ Engl J Med. 2005;353:229-37.

5. Kabat GC, Jones JG, Olson N, et al. A multi-center prospective cohort study of benign breast disease and risk of subsequent breast cancer. Cancer Causes Control. 2010;21:821-8.

6. Perry N, Broeders M, de Wolf C, Tornberg S, Holland R, von Karsa L. European guidelines for quality assurance in breast cancer screening and diagnosis (IV Edition). Luxembourg: Office for Official Publications of the European Communities; 2006. Available from: http://screening.iarc.fr/doc/ND7306954ENC_002.pdf. Accessed July 19, 2017.

7. Schousboe JT, Kerlikowske K, Loh A, Cummings SR. Personalizing mammography by breast density and other risk factors for breast cancer: analysis of health benefits and cost-effectiveness. Ann Intern Med. 2011;155:10-20.

8. Vilaprinyo $\mathrm{E}$, Forne $\mathrm{C}$, Carles $\mathrm{M}$, et al. Cost-effectiveness and harm-benefit analyses of risk-based screening strategies for breast cancer. PLoS One. 2014;9(2):e86858.

9. Jacobs TW, Byrne C, Colditz G, Connolly JL, Schnitt SJ. Pathologic features of breast cancers in women with previous benign breast disease. Am J Clin Pathol. 2001;115:362-9.

10. Mitro SD, Ali-Fehmi R, Bandyopadhyay S, et al. Clinical characteristics of breast cancers in AfricanAmerican women with benign breast disease: a comparison to the surveillance, epidemiology, and end results program. Breast J. 2014;20:571-7.

11. Visscher DW, Frost MH, Hartmann LC, et al. Clinicopathologic features of breast cancers that develop in women with previous benign breast disease. Cancer. 2016;122:378-85.

12. Ascunce N, Salas D, Zubizarreta R, Almazan R, Ibanez J, Ederra M. Cancer screening in Spain. Ann Oncol. 2010;21 Suppl 3:iii43-iii51.

13. Castells X, Sala M, Ascunce N, Salas D, Zubizarreta R, Casamitjana M. Descripción del cribado del cáncer en España. [Description of cancer screening in Spain. DESCRIC Project]. Madrid: Plan de Calidad para el Sistema Nacional de Salud. Ministerio de Sanidad y Consumo; 2007. Available from: https://www.sergas.es/Docs/Avalia-t/AATRM200601.pdf. Accessed July 19, 2017.

14. Hammond MEH, Hayes DF, Dowsett M, et al. American Society of Clinical Oncology/College of American Pathologists guideline recommendations for immunohistochemical testing of estrogen and progesterone receptors in breast cancer (unabridged version). Arch Pathol Lab Med. 2010;134:e48-72. 
15. Wolff AC, Hammond MEH, Schwartz JN, et al. American Society of Clinical Oncology/College of American Pathologists guideline recommendations for human epidermal growth factor receptor 2 testing in breast cancer. Arch Pathol Lab Med. 2007;131:18-43.

16. Elston CW, Ellis IO. Pathological prognostic factors in breast cancer. I. The value of histological grade in breast cancer: experience from a large study with long-term follow-up. Histopathology. 1991;19:403-10.

17. Dupont WD, Page DL. Risk factors for breast cancer in women with proliferative breast disease. $N$ Engl J Med. 1985;312:146-51.

18. Nassar A, Hoskin TL, Stallings-Mann ML, et al. Ki-67 expression in sclerosing adenosis and adjacent normal breast terminal ductal lobular units: a nested case-control study from the Mayo Benign Breast Disease Cohort. Breast Cancer Res Treat. 2015;151:89-97.

19. Domingo L, Romero A, Blanch J, et al. Clinical and radiological features of breast tumors according to history of false-positive results in mammography screening. Cancer Epidemiol. 2013;37:660-5.

20. Sasaki $\mathrm{Y}$, Miki $\mathrm{Y}$, Hirakawa $\mathrm{H}$, et al. Immunolocalization of estrogen-producing and metabolizing enzymes in benign breast disease: comparison with normal breast and breast carcinoma. Cancer Sci. 2010;101:2286-92.

21. Tice JA, Miglioretti DL, Li C-S, Vachon CM, Gard CC, Kerlikowske K. Breast Density and Benign Breast Disease: Risk Assessment to Identify Women at High Risk of Breast Cancer. J Clin Oncol. 2015;33:3137-43. 
Table 1. Clinical and histological characteristics of breast carcinomas for women with and without a previous pathological diagnosis of benign breast disease. All breast carcinomas $(\mathrm{N}=6,645)$

\begin{tabular}{|c|c|c|c|}
\hline Characteristic & $\begin{array}{l}\text { No previous benign } \\
\text { breast disease; } \\
\quad(n=6407)\end{array}$ & $\begin{array}{l}\text { Previous Benign } \\
\text { Breast Disease; } \\
\quad(n=238)\end{array}$ & $p^{*}$ \\
\hline \multicolumn{4}{|l|}{ Age at last screen } \\
\hline $50-54$ & $1335(20.8)$ & 45 (18.9) & \\
\hline $55-59$ & $1730(27.0)$ & $53(22.3)$ & \\
\hline $60-64$ & $1847(28.8)$ & $82(34.5)$ & \\
\hline $65-69$ & $1495(23.3)$ & $58(24.4)$ & \\
\hline \multicolumn{4}{|l|}{ Detection mode } \\
\hline Screen detected & $4299(67.1)$ & $151(63.4)$ & \\
\hline Interval cancer & 2108 (32.9) & $87(36.6)$ & \\
\hline Breast cancer type & & & $<0.05$ \\
\hline DCIS & 737 (13.6) & $49(22.1)$ & \\
\hline Invasive & $4678(86.4)$ & $173(77.9)$ & \\
\hline Unknown & 992 & 16 & \\
\hline
\end{tabular}

DCIS: ductal carcinoma in situ; Invasive: invasive carcinoma $¥$ Different at $p<0.05$ in a two-sided test of equality for column proportions (z-test). The unknown category is excluded in the tests for differences. Tests are adjusted using the Bonferroni correction for multiple comparison. 
Table 2. Clinical and histological characteristics of breast carcinomas for women with and without a previous pathological diagnosis of benign breast disease. Invasive cancinomas only $(\mathrm{N}=4,851)$

\begin{tabular}{|c|c|c|c|}
\hline Characteristic & $\begin{array}{l}\text { No previous benign } \\
\text { breast disease; } \\
(n=4,678)\end{array}$ & $\begin{array}{c}\text { Previous } \\
\text { Benign Breast } \\
\text { Disease; } \\
(n=173)\end{array}$ & $p^{*}$ \\
\hline \multicolumn{4}{|l|}{ Grade } \\
\hline 1 & $724(25.2)$ & $42(30.2)$ & \\
\hline 2 & $1310(45.5)$ & $64(46.0)$ & \\
\hline 3 & $843(29.3)$ & $33(23.7)$ & \\
\hline Unknown & 1801 & 34 & \\
\hline Tumor Size & & & $<0.05$ \\
\hline$\leq 2 \mathrm{~cm}$ & 3057 (73.6) & $100(63.3)$ & \\
\hline$>2 \mathrm{~cm}$ & $1096(26.4)$ & $58(36.7)$ & \\
\hline Unknown & 525 & 15 & \\
\hline \multicolumn{4}{|l|}{ Lymph nodes } \\
\hline Negative & $2871(72.0)$ & 112 (67.9) & \\
\hline Positive & $1118(28.0)$ & $53(32.1)$ & \\
\hline Unknown & 689 & 8 & \\
\hline Metastasis & & & $<0.05$ \\
\hline Negative & 3467 (98.3) & $145(94.8)$ & \\
\hline Positive & $60(1.7)$ & $8(5.2)$ & \\
\hline Unknown & 1151 & 20 & \\
\hline \multicolumn{4}{|l|}{ ER status } \\
\hline Negative & $442(17.7)$ & $25(16.2)$ & \\
\hline Positive & $2051(82.3)$ & $129(83.8)$ & \\
\hline Unknown & 2185 & 19 & \\
\hline \multicolumn{4}{|l|}{ PR status } \\
\hline Negative & 731 (29.5) & $50(32.5)$ & \\
\hline Positive & 1751 (70.5) & $104(67.5)$ & \\
\hline Unknown & 2196 & 19 & \\
\hline \multicolumn{4}{|l|}{ HER2 status } \\
\hline Negative & 1270 (84.9) & $130(87.2)$ & \\
\hline Positive & $225(15.1)$ & $19(12.8)$ & \\
\hline Unknown & 3183 & 24 & \\
\hline Ki-67 status & & & $<0.05$ \\
\hline Low & $1012(66.3)$ & $46(49.5)$ & \\
\hline High & $514(33.7)$ & 47 (50.5) & \\
\hline Unknown & 3152 & 80 & \\
\hline
\end{tabular}

₹ Different at $p<0.05$ in a two-sided test of equality for column proportions (z-test). The unknown category is excluded in the tests for differences. Tests are adjusted using the Bonferroni correction for multiple comparison. 
Table 3: Clinical and histological characteristics of screen detected and interval carcinomas by history of a previous pathological diagnosis of benign breast disease

\begin{tabular}{|c|c|c|c|c|c|c|}
\hline \multirow[b]{2}{*}{ Characteristic } & \multicolumn{3}{|c|}{ Screen detected cancer } & \multicolumn{3}{|c|}{ Interval cancer } \\
\hline & $\begin{array}{c}\text { No previous } \\
\text { benign breast } \\
\text { disease; } \\
(n=4,299)\end{array}$ & $\begin{array}{c}\text { Previous } \\
\text { Benign Breast } \\
\text { Disease; } \\
(n=151)\end{array}$ & $p^{*}$ & $\begin{array}{c}\text { No previous } \\
\text { benign breast } \\
\text { disease; } \\
(n=2,108)\end{array}$ & $\begin{array}{c}\text { Previous } \\
\text { Benign Breast } \\
\text { Disease; }(n=87)\end{array}$ & $p^{*}$ \\
\hline \multicolumn{7}{|c|}{ All breast cancer cases, $(n=6,645)$} \\
\hline Breast cancer type & & & $<0.05$ & & & $<0.05$ \\
\hline DCIS & $676(16.1)$ & $35(23.2)$ & & $61(5.0)$ & $14(19.7)$ & \\
\hline Invasive & 3514 (83.9) & $116(76.8)$ & & $1164(95.0)$ & $57(80.3)$ & \\
\hline Unknown & 109 & 0 & & 883 & 16 & \\
\hline \multicolumn{7}{|c|}{ Invasive cancers only, (n=4,851) } \\
\hline Grade & & & $<0.05$ & & & \\
\hline 1 & $618(27.6)$ & $34(35.4)$ & & $106(16.7)$ & $8(18.6)$ & \\
\hline 2 & $1042(46.5)$ & $50(52.1)$ & & $268(42.1)$ & $14(32.6)$ & \\
\hline 3 & $581(25.9)$ & $12(12.5)$ & & $262(41.2)$ & $21(48.8)$ & \\
\hline Unknown & $1273(0.0)$ & $20(0.0)$ & & $528(0.0)$ & $14(0.0)$ & \\
\hline \multicolumn{7}{|l|}{ Tumor Size } \\
\hline$\leq 2 \mathrm{~cm}$ & $2610(80.7)$ & $81(74.3)$ & & $447(48.6)$ & $19(38.8)$ & \\
\hline$>2 \mathrm{~cm}$ & $623(19.3)$ & $28(25.7)$ & & $473(51.4)$ & $30(61.2)$ & \\
\hline Unknown & 281 & 7 & & 244 & 8 & \\
\hline \multicolumn{7}{|l|}{ Lymph nodes } \\
\hline Negative & 2362 (78.6) & $89(78.8)$ & & $509(51.7)$ & $23(44.2)$ & \\
\hline Positive & $643(21.4)$ & $24(21.2)$ & & $475(48.3)$ & $29(55.8)$ & \\
\hline Unknown & 509 & 3 & & 180 & 5 & \\
\hline \multicolumn{7}{|l|}{ Metastasis } \\
\hline Negative & 2952 (99.2) & 109 (98.2) & & 515 (93.5) & $36(85.7)$ & \\
\hline Positive & $24(0.8)$ & $2(1.8)$ & & $36(6.5)$ & $6(14.3)$ & \\
\hline Unknown & 538 & 5 & & 613 & 15 & \\
\hline \multicolumn{7}{|l|}{ ER status } \\
\hline Negative & 357 (16.4) & $12(11.2)$ & & $85(27.0)$ & $13(27.7)$ & \\
\hline Positive & 1821 (83.6) & $95(88.8)$ & & $230(73.0)$ & $34(72.3)$ & \\
\hline Unknown & 1336 & 9 & & 849 & 10 & \\
\hline \multicolumn{7}{|l|}{ PR status } \\
\hline Negative & $597(27.5)$ & $29(27.4)$ & & $134(42.5)$ & $21(43.8)$ & \\
\hline Positive & $1570(72.5)$ & $77(72.6)$ & & $181(57.5)$ & $27(56.3)$ & \\
\hline Unknown & 1347 & 10 & & 849 & 9 & \\
\hline \multicolumn{7}{|l|}{ HER2 status } \\
\hline Negative & 1105 (84.5) & $91(88.3)$ & & $165(87.8)$ & $39(84.8)$ & \\
\hline Positive & $202(15.5)$ & $12(11.7)$ & & $23(12.2)$ & $7(15.2)$ & \\
\hline Unknown & 2207 & 13 & & 976 & 11 & \\
\hline Ki-67 status & & & $<0.05$ & & & $<0.05$ \\
\hline Low & 871 (64.2) & $33(50.0)$ & & 141 (82.9) & $13(48.1)$ & \\
\hline High & 485 (35.8) & $33(50.0)$ & & $29(17.1)$ & 14 (51.9) & \\
\hline Unknown & 2158 & 50 & & 994 & 30 & \\
\hline
\end{tabular}


TABLE 4. Clinical and histological characteristics of breast carcinomas by histologic category of pathologically diagnosed benign breast disease.

\begin{tabular}{|c|c|c|c|c|c|}
\hline \multirow[b]{2}{*}{ Characteristic } & \multirow{2}{*}{$\begin{array}{c}\text { No previous } \\
\text { benign breast } \\
\text { disease, } \\
(n=6,407)\end{array}$} & \multicolumn{3}{|c|}{ Benign breast disease } & \multirow[b]{2}{*}{$p^{¥}$} \\
\hline & & $\begin{array}{c}\text { Negative for } \\
\text { malignant cells, } \\
(n=99)\end{array}$ & $\begin{array}{c}\text { Non- } \\
\text { proliferative, } \\
(n=102) \\
\end{array}$ & $\begin{array}{c}\text { Proliferative } \\
\text { with or withiout } \\
\text { atypia, }(n=37)\end{array}$ & \\
\hline \multicolumn{6}{|c|}{ All breast cancer cases, $(n=6,645)$} \\
\hline Breast cancer type & & & & & $<0.05$ \\
\hline DCIS & $737(13.6)^{*}$ & $20(22.2)$ & $22(23.2) *$ & 7 (18.9) & \\
\hline Invasive & $4678(86.4)$ & $70(77.8)$ & $73(76.8)$ & $30(81.1)$ & \\
\hline Unknown & 992 & 9 & 7 & 0 & \\
\hline \multicolumn{6}{|c|}{ Invasive cancers only, $(n=4,851)$} \\
\hline \multicolumn{6}{|l|}{ Grade } \\
\hline 1 & $724(25.2)$ & $20(33.3)$ & $18(31.6)$ & $4(18.2)$ & \\
\hline 2 & $1310(45.5)$ & $29(48.3)$ & $24(42.1)$ & $11(50.0)$ & \\
\hline 3 & $843(29.3)$ & $11(18.3)$ & $15(26.3)$ & $7(31.8)$ & \\
\hline Unknown & 1801 & 10 & 16 & 8 & \\
\hline Tumor Size & & & & & $<0.05$ \\
\hline$\leq 2 \mathrm{~cm}$ & $3057(73.6) *$ & $47(71.2)$ & $35(53.8) *$ & $18(66.7)$ & \\
\hline$>2 \mathrm{~cm}$ & $1096(26.4)$ & $19(28.8)$ & $30(46.2)$ & $9(33.3)$ & \\
\hline Unknown & 525 & 4 & 8 & 3 & \\
\hline \multicolumn{6}{|l|}{ Lymph node statut } \\
\hline Negative & 2871 (72.0) & $51(75.0)$ & $41(59.4)$ & $20(71.4)$ & \\
\hline Positive & 1118 (28.0) & $17(25.0)$ & $28(40.6)$ & $8(28.6)$ & \\
\hline Unknown & 689 & 2 & 4 & 2 & \\
\hline Metastasis & & & & & $<0.05$ \\
\hline Negative & $3467(98.3)$ * & $60(96.8)$ & $59(95.2)$ & $26(89.7) *$ & \\
\hline Positive & $60(1.7)$ & $2(3.2)$ & $3(4.8)$ & $3(10.3)$ & \\
\hline Unknown & 1151 & 8 & 11 & 1 & \\
\hline \multicolumn{6}{|l|}{ ER status } \\
\hline Negative & $442(17.7)$ & $5(8.6)$ & $15(22.7)$ & $5(16.7)$ & \\
\hline Positive & $2051(82.3)$ & $53(91.4)$ & $51(77.3)$ & $25(83.3)$ & \\
\hline Unknown & 2185 & 12 & 7 & 0 & \\
\hline \multicolumn{6}{|l|}{ PR status } \\
\hline Negative & $731(29.5)$ & $18(30.5)$ & $25(38.5)$ & $7(23.3)$ & \\
\hline Positive & 1751 (70.5) & $41(69.5)$ & $40(61.5)$ & $23(76.7)$ & \\
\hline Unknown & 2196 & 11 & 8 & 0 & \\
\hline \multicolumn{6}{|l|}{ HER2 status } \\
\hline Negative & 1270 (84.9) & $48(85.7)$ & $55(87.3)$ & $27(90.0)$ & \\
\hline Positive & $225(15.1)$ & $8(14.3)$ & $8(12.7)$ & $3(10.0)$ & \\
\hline Unknown & 3183 & 14 & 10 & 0 & \\
\hline Ki-67 status & & & & & $<0.05$ \\
\hline Negative & $1012(66.3)^{*}$ & $24(60.0)$ & $11(34.4)^{*}$ & $11(52.4)$ & \\
\hline Positive & $514(33.7)$ & $16(40.0)$ & $21(65.6)$ & $10(47.6)$ & \\
\hline Unknown & 3152 & 30 & 41 & 9 & \\
\hline \multicolumn{6}{|c|}{ DCIS: ductal carcinoma in situ; Invasive: invasive carcinoma } \\
\hline $\begin{array}{l}{ }^{*} \text { Different at } p<0.0 \\
\text { excluded in the test } \\
\text { using the Bonferron }\end{array}$ & $\begin{array}{l}\text {-sided test of eq } \\
\text { rences. Tests ad } \\
\text { on }\end{array}$ & $\begin{array}{l}\text { lity for column pro } \\
\text { ted for all pairwise }\end{array}$ & $\begin{array}{l}\text { tions (z-test). } \\
\text { nparisons with }\end{array}$ & $\begin{array}{l}\text { e unknown catego } \\
\text { each tumor chara }\end{array}$ & $\begin{array}{l}\text { ory is } \\
\text { acteristic }\end{array}$ \\
\hline
\end{tabular}


Table 5. Odds ratio of occurrence of selected clinical and histological characteristics of breast carcinomas for women with and without a previous pathological diagnosis of benign breast disease. Invasive carcinomas only $(\mathrm{N}=4,851)$.

\begin{tabular}{lccc}
\hline & $\begin{array}{c}\text { Previous } \\
\text { Negative test, } \\
\text { Tumor characteristic * }\end{array}$ & $\begin{array}{c}\text { Unadjusted OR } \\
(\mathbf{n}=\mathbf{4 , 6 7 8 )}\end{array}$ & $\begin{array}{c}\text { Pdjusted OR } \\
\mathbf{( 9 5 )}\end{array}$ \\
\hline Grade (3 vs 1 \& 2) & Ref. & $0.75(0.50-1.12)$ & $0.71(0.48-1.07)$ \\
Tumor size (> 2cm vs $\leq 2 \mathrm{~cm})$ & Ref. & $1.62(1.16-2.25)$ & $1.46(1.03-2.08)$ \\
Lymph nodes (positive vs negative) & Ref. & $1.21(0.87-1.70)$ & $1.12(0.79-1.59)$ \\
Metastasis (positive vs negative) & Ref. & $3.19(1.50-6.80)$ & $2.66(1.21-5.86)$ \\
ER status (positive vs negative) & Ref. & $1.11(0.71-1.73)$ & $1.22(0.78-1.92)$ \\
PR status (positive vs negative) & Ref. & $0.87(0.61-1.23)$ & $0.96(0.67-1.37)$ \\
HER2 status (positive vs negative) & Ref. & $0.83(0.50-1.36)$ & $0.86(0.52-1.43)$ \\
Ki-67 status (high vs low) & Ref. & $2.01(1.32-3.06)$ & $1.93(1.24-2.99)$ \\
\hline
\end{tabular}

* Based on 8 separated models.

${ }^{*}$ Adjusted for detection mode (screen detected or interval cancer), age at last screen, and calendar year at last screen. 
Figure legend:

Figure 1: Flow chart of study participants.

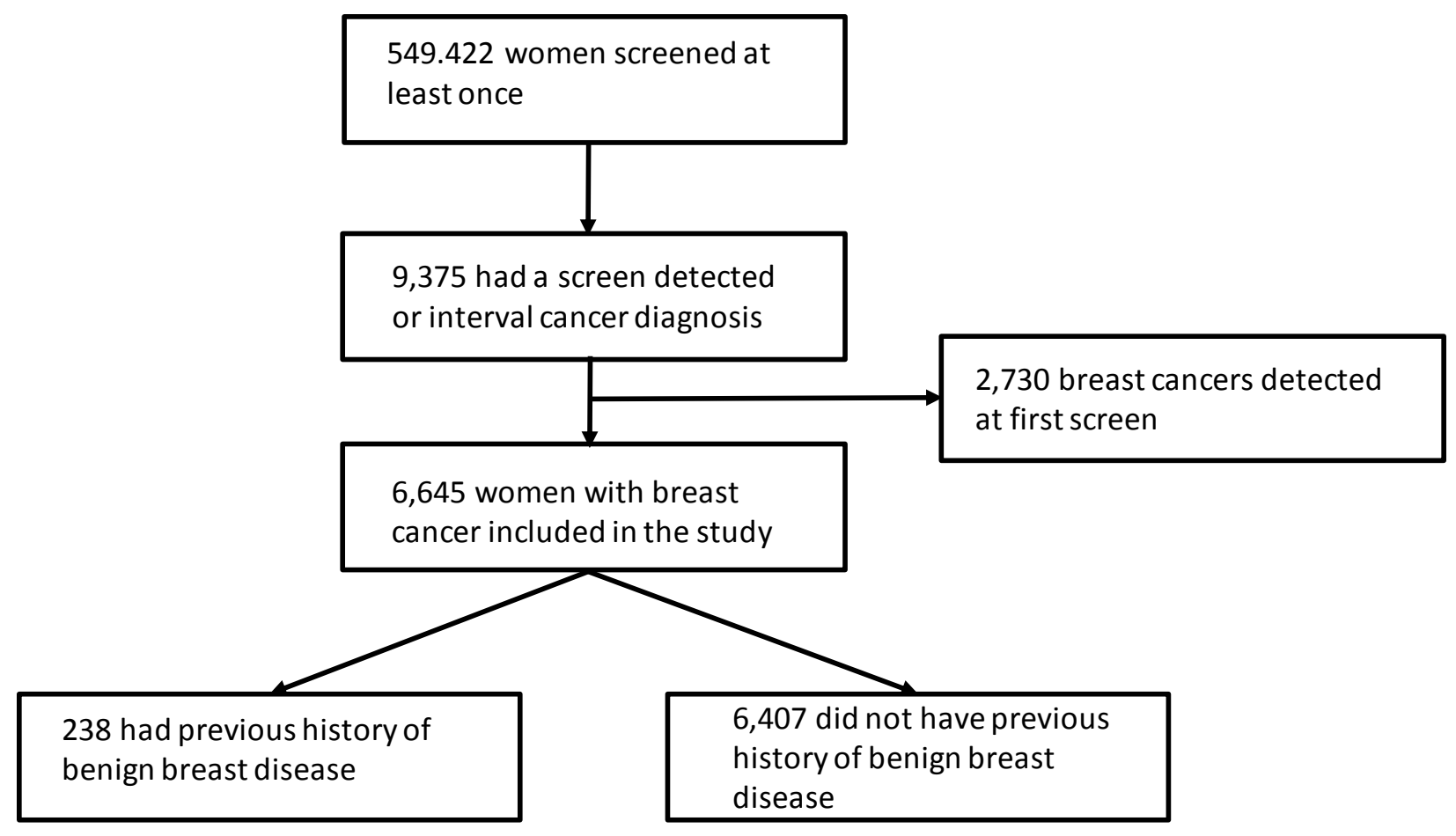

